\title{
The Evolution of Agricultural Engineering Education in China
}

\author{
Lijuan Shi ${ }^{1,2, a}$, Minli Yang ${ }^{2, b}$ \\ ${ }^{1}$ China Agricultural University Library, Beijing, China \\ ${ }^{2}$ College of Engineering, China Agricultural University, Beijing,China \\ ashlij@cau.edu.cnl, ${ }^{b}$ qyang@cau.edu.cn
}

\begin{abstract}
Keywords: Agricultural Engineering; Liberal Education; Professional Education; Talent Training Abstract. The evolution of agricultural engineering (AE) education in China is described in this paper. In the help of the American Committee on Agricultural Engineering, the AE major based on liberal education model was established in 1947. Five years later, the majors such as agricultural mechanization, field water conservancy, rural electrification and farm machine featured professional education were established base on the guidance of the former Soviet Union (USSR), until the discipline of AE was officially established in 1979. The change of talent training goals was considered to represent a paradigm shift from a focus on 'professional' content to put more emphasis on 'liberal' content and this reorientation was further reflected by changes in the curriculum to increase the content of general education courses since 1980s. In general, the fusion of patterns between liberal education and professional education is an inevitable trend in the development of AE education in China.
\end{abstract}

\section{Introduction}

In the Europe and North America region, the discipline of agricultural engineering has undergone considerable changes in orientation during the past decade in response to both external and internal pressures affecting universities and agriculture-related programs[1]. A challenge facing Agricultural Engineering (AE) education in China is how to cultivate the right talents to meet the demand of modern agriculture and rural development needs now. Both the 12th 5-year National Modern Agriculture Development Plan (2011-2015) and Outline of China's National Plan for Medium and Long-term Education Reform and Development(2010-2020) underscore the importance of strengthen the supporting role of S\&T and talents in agriculture. As the part of agricultural higher education in the country, AE education is expected to play a leading role in the realization of the agricultural mechanization and modernization.

\section{Liberal education pattern (1948-52)}

AE education in the North America region has always been a university-based academic discipline based in the broad fields of engineering, the natural sciences and social sciences, and it was also known as liberal education. In the 20th century, liberal education was defined as a well-rounded educational program, and not tied to certain academic subjects. In 1945, Harvard University published General Education in a Free Society and pointed out that the aim of higher education was to cultivate 'whole man' and 'good man '. According to the book, a graduate should be equipped with four basic capabilities: effective thinking, communication, the making of relevant judgment and the distinguishing values [2]. In order to have such capabilities, all-round knowledge should be passed on to students including human science, social science and natural science which were exactly covered by the courses of general education.

Early in the year 1945, an educational program for the introduction of improved production techniques into the agriculture of China was approved by the American International Harvester Company, and which led to selection the four experts of the Committee on Agricultural Engineering (CAE). In the help of the CAE, the AE major was established in the University of Nanking and National Central University. Table 1 shows a curriculum of the AE program offered during the 1948 
in the department of agricultural engineering at the National Central University [3]. The curriculum and training pattern of AE education mainly follow the United States, which emphasized broad knowledge as well as strong intellectual and practical skills such as communication, analytical and problem-solving skills, and a demonstrated ability to apply knowledge and skills in real-world settings (Fig.1).

Table.1 Curriculum in Agricultural Engineering Department, National Central University

\begin{tabular}{|l|l|l|l|}
\hline \multicolumn{1}{|c|}{ Freshman } & \multicolumn{1}{|c|}{ Sophomore } & \multicolumn{1}{c|}{ Junior } & \multicolumn{1}{c|}{ Senior } \\
\hline Principles of Government & Mechanism & Heat Power Engineering & Farm Structures \\
\hline Chinese & Applied Mechanics & Machine Design & Electrical Engineering Lab \\
\hline Freshman English & Materials of & Testing of Materials & Soil and Water Conservation \\
\hline $\begin{array}{l}\text { Differential \& Integral } \backslash \\
\text { Calculus }\end{array}$ & Empirical Design & Hydraulics & Repair of Farm Machinery \\
\hline General Physics & Machine Tool Work & General Horticulture & Farm Power \\
\hline Descriptive Geometry & Pattern Making & Electrical Engineering & Soil and Fertilizers \\
\hline Forging & Differential Equations & Farm Shop & Agricultural Engineering Seminar \\
\hline $\begin{array}{l}\text { General Concept of } \\
\text { Agriculture }\end{array}$ & General Chemistry & Crop Production & Physical Education \\
\hline Farm Practice & Strength of Materials & Heat Power Engineering & Rural Industry \\
\hline Mechanical Drawing & Surveying & Fab Machinery & Dairy Machinery \\
\hline Foundry & Heat Power & Electrical Engineering & General Plant Pathology or \\
Engineering & Physical Education & Advanced Farm Shop & Agricultural Engineering Seminar \\
\hline Military Training & & Agricultural Economics & Thesis \\
\hline Physical Education & & Animal Husbandry or & Physical Education \\
\hline & Forestry & \\
\hline & Physical Education & \\
\hline
\end{tabular}

It is obvious that the curriculum was deliberately designed to produce AE generalists who have the strong practical skills and broad major field. However, the political conditions in China made it necessary for AE education to give up the America' pattern in the early 1950s.

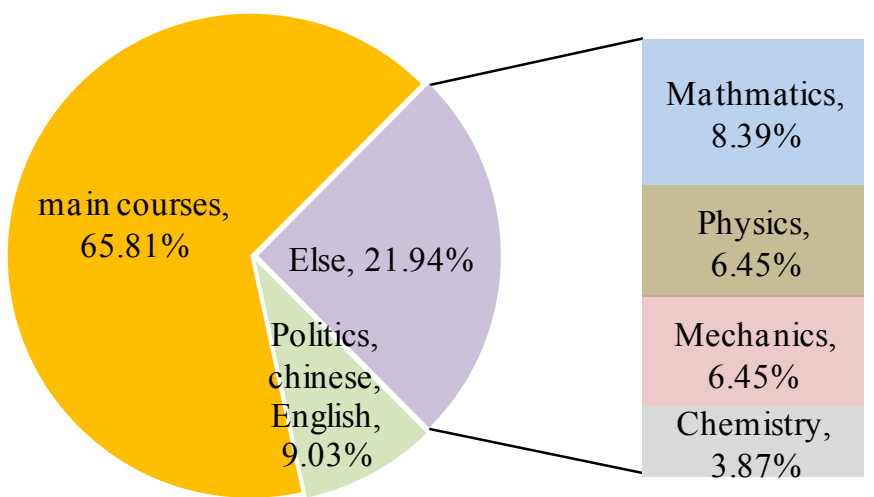

Fig.1 Elements of the AE program at National Central University in 1948/1949

\section{Professional Education Pattern (1953-77)}

After the First World War, the former Soviet Union (USSR) created a series of free-standing higher education institutes whose admission, curricula, and postsecondary systems were centrally controlled in strict conformity with political doctrine. The higher education institutions had two tasks: the first is to train qualified specialists for the national economy, and the second is to be the scientific potential of the country [4].This special higher education system was narrowly defined professional education. In 1953, affected by the special environment of political economy, the AE education in China had 
stepped to imitate the socialist higher education system in former Soviet Union (USSR), and had abolished the American education system.

The paradigm of professional education was closely related to the system of planned economy. In the early foundation of the USSR, in order to satisfy the requirements of national industrial planning, according to the specific requirements of national economic departments, comprehensive universities and specific single-subject colleges were established to respectively cultivate specialists in different field under the close bureaucratic control and tight policy coordination. Graduates were assigned to jobs according to the sector of their particular school. Based on the professional talent training model, the specialists made significant contributions to the realization of national economic construction and implementation of industrialization in USSR .

Beijing Agricultural Mechanization College (BAMC), founded in 1952, was the first institute in China covering all major fields in agricultural engineering, imitation institute mechanization and electrification of agriculture model in USSR. Fig. 2 shows elements of the agricultural mechanization program offered during the 1952/1953 in BAMC.

Comparison of the agricultural mechanization curriculum (Fig.2) with a generalized framework for similar programs offered by National Central University in 1948 (Fig.1) shows that both exist significant difference in the distribution of courses, the difference is mainly accounted for the main courses included the basic and professional courses in major field as well as politics and foreign language. The main courses in National Central University (liberal education model) are close to 66\% and involve 33 courses; however, about $56 \%$ of the courses in BAMC (professional education model) only cover 18 courses. The main purpose of curriculum for professional education was obviously to train highly skilled, educated specialists with in-depth knowledge of the special major field and mastery the practical skills met the demand their professions practicing in a very short period of time. In a planned economy, this pattern corresponded to the demand of national development. Moreover, in the special period, the need for Russian was increasing for graduates with greater foreign language skills.

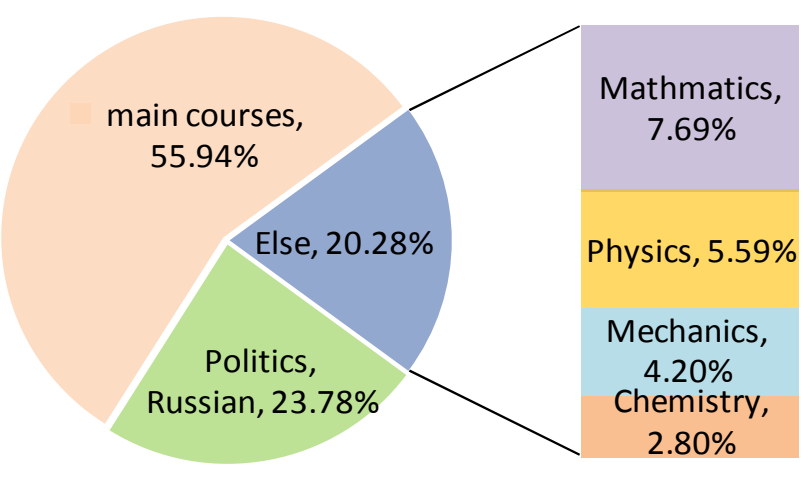

Fig.2 Elements of agricultural mechanization program at BAMC in 1952

Prior to 1980, the specialty setting mainly based on industrial categories and products and emphasized professional career and vocational training which were directly related with economic construction, such as the Automobile and Tractor, Tractor, Automobile, Design and Manufacture of Tractor, Design and Manufacture of Automobile, etc. In addition, graduates are uniformly assigned by government, and they immediately went to work after short-term internship in enterprises. The professional education pattern had single knowledge structure and insufficient within humanities and social science knowledge in terms of curriculum, as well as all courses were compulsory courses. Although graduates could be competent work quickly, they are relatively short of creativity and adaptive ability facing the swift change of science and technology, also, more lack of entrepreneurship. 


\section{Reform of Talent Training Pattern (1978 and Beyond)}

Since the reform and opening-up in 1978, the globalization of higher education was increasingly accelerated. The government found that the graduates lacked the broad knowledge and creative ability and did not meet the needs of the social. The model of AE talent training has experienced dramatic transformations since 1980s.

Widen Specialty Caliber, Strengthen Basic Knowledge (1980s). In 1980s, Government proposed the guidelines for higher education reform, pointed out that reform should focus on widen specialty caliber and strengthen basic knowledge. The reform demonstrated the following features:

The first was greatly to adjust disciplines and broaden the caliber of specialty. In 1984, the Ministry of Education solicited opinions on the revised version of the catalogs of majors for undergraduate students in agricultural and engineering institutes of higher learning. The revised version increased the subjects of the agricultural engineering for the first time. The mergence of majors was the main features of this revision and the wider of specialty caliber. For instance, the newly established major of the Automobile and Tractor was actually the combination of majors of the Automobile and Tractor, Tractor, Automobile, Design and Manufacture of Tractor, etc, all of which were featured in the original catalog.

The second was to set goals for ability training and adjust course structure which would achieve those goals, the efforts concentrated on developing elective courses to students, emphasis on strengthen basic knowledge in humanities, social sciences and modern technology in agricultural engineering, to strengthen written and oral communication, through fusion and integrated education with relatively small changes such as adding a writing course or literature retrieval in curricular reform.

During the mid-to late 1980s, the reform mainly focused on the knowledge structure and ability training adjustment, and provided the range of course options to more comprehensive and flexibility.

Optimized Curriculum System, Strengthen ability Cultivation (1990s). In 1990s, along with the transition of the planned economy to market economy in China, labor markets became free and meant that graduates could work wherever they wanted, the companies could freely chose who they wanted, those choices were completely determined by market-based economy. The most important challenge faced by the AE higher education was how to quickly adapt to transition from the former socialist centrally planned system to the open talent market. Furthermore, how to train a student's creative spirit and comprehensive ability has gradually found its place in Chinese higher education. All of changes were immediate and they required an immediate response on the system of higher education.

The curriculum is the main factors that affect the knowledge structure and ability of talents'. The optimization of the AE curriculum has established a scheme of curriculum teaching which increased basic science and subject common courses such as introduction to computer science, fundamentals of programming, Chinese and agricultural economics and so on. The new curricula permitted considerable freedom in the selection of courses and reduced the workload of professional courses. What's more, the curriculum system strived to stimulate students' motivation and tried to help students lay a solid foundation in agricultural engineering basics and offer analytic, problem solving ability with a wide array of elective courses.

Reformed General Education, Strengthen Quality-Oriented Education (2000 and Beyond). Since 2000, the competencies are described in the higher engineering education for student learning are the knowledge, ability and qualities that contribute to students becoming critical thinkers and ethical citizens with an entrepreneurial spirit. The universities realized that a four-year college course should not be confined to a narrow field of study, and it should provide the students with broad training in both liberal and vocational subjects. The liberal education should be strengthened for the purpose of pursuing the quality-oriented education, which is focused on the education for promote into the comprehensive development and improvement of the overall quality [5]. This model was also defined inter-disciplinary talent cultivation model. 
In the early 21 st century, China launched new round of reform in higher education and emphasized on enhancing students' integrative abilities and broadening their knowledge areas. The most significant change made in the courses is that the module of general education was first created, as well as the optional courses of general education. The general education courses, such as Ideological and Moral Culture \& Basis of Law, Basis Discipline of Marxist, Modern Chinese History Program, Mao Zedong Thought, Theories of Deng Xiaoping and Introduction to the Important Though of Three Representatives, physical education, fundament of computer, and English were required by the Ministry of Education. In addition, the general education optional course can be freely set by the university with the reference of Harvard's core curriculum, so as to prepare the graduates for all-round development and meet future challenges better.

As an example, the general education curricula (2008 Edition) implemented by the agricultural mechanization and automation program in China Agricultural University, which was formed by merging BAMC and Beijing Agricultural University in 1995, is divided into two parts: the Ministry of Education requirements and the university requirements. The optional course of university requirements is divided into three fields as literature and arts, humanities and social sciences, economics and management, each field should be completed at least 4 credits(Table 2). Every student must complete 45 credits' general education curriculum. It is obvious that the objective of the general education project is conductive to promote the students breadth-of-knowledge areas and comprehensive literacy (quality-oriented education), including effective English communication, technological skills, critical thinking, logical reasoning, multidiscipline approaches to solve problems, and information literacy, etc. This type of education model can prepare students for many fields in today's workplace.

Table.2 General education curricula in China Agricultural University (2008 Edition)

\begin{tabular}{|c|c|c|c|}
\hline Types & Names & Credits & Notes \\
\hline \multirow{4}{*}{$\begin{array}{l}\text { Compulsory } \\
\text { Courses }\end{array}$} & Ideological and Moral Culture \& Basis of Law & 3 & \multirow{8}{*}{$\begin{array}{l}\text { the Ministry of } \\
\text { Education } \\
\text { Requirements }\end{array}$} \\
\hline & Basis Discipline of Marxist & 3 & \\
\hline & Modern Chinese History Program & 2.5 & \\
\hline & $\begin{array}{l}\text { Mao Zedong Thought、Theories of Deng Xiaoping and Introduction to the } \\
\text { Important Though of Three Representatives }\end{array}$ & 3.5 & \\
\hline \multirow{7}{*}{$\begin{array}{l}\text { Elective } \\
\text { Courses }\end{array}$} & College English & 12 & \\
\hline & The Basics Computer of College & 2 & \\
\hline & C Programming & 3 & \\
\hline & Physical Education Category & 4 & \\
\hline & Literature and Art Category & 4 & \multirow{3}{*}{$\begin{array}{c}\text { University } \\
\text { Requirements }\end{array}$} \\
\hline & Humanities and Social Sciences Category & 4 & \\
\hline & Economics and Management Category & 4 & \\
\hline
\end{tabular}

\section{Impacts of Pattern Reform}

Since the 1990s, China has carried out reform of state owned enterprises through the introduction of the shareholding system and made great efforts to support the development of mixed economic system, and industrial and agricultural productivities have continued to improve [6]. Meanwhile, college graduates' employment system has experienced changes from planned distribution by the government to bilateral selection between the employer and the graduates [7]. In recent years, the cultivation of creative ability and entrepreneurial spirit based on the general education propelled the changing of the traditional employment concept. The 2014 annual report on employment quality from agricultural universities indicated that the private sector are by far the largest employers of agricultural engineering graduates, including freelance, self-employment and Joint venture. 
According to the report of China Higher Education Student Information and Career Center, that the employment rate of college graduates majoring in the agricultural mechanization and automation was more than $80 \%$ during the period 2004-2011(Fig.3). It is clearly that the employment rate of agricultural mechanization graduates (2004-2007) was not only declining, but was below the average of engineering graduates. However, it was impressive that the employment rate of agricultural mechanization graduates was rising from 2008, and experienced above-average level increases in engineering graduates. In many ways, a liberal education is education for life. It prepares graduates who can adapt an ever-changing world.

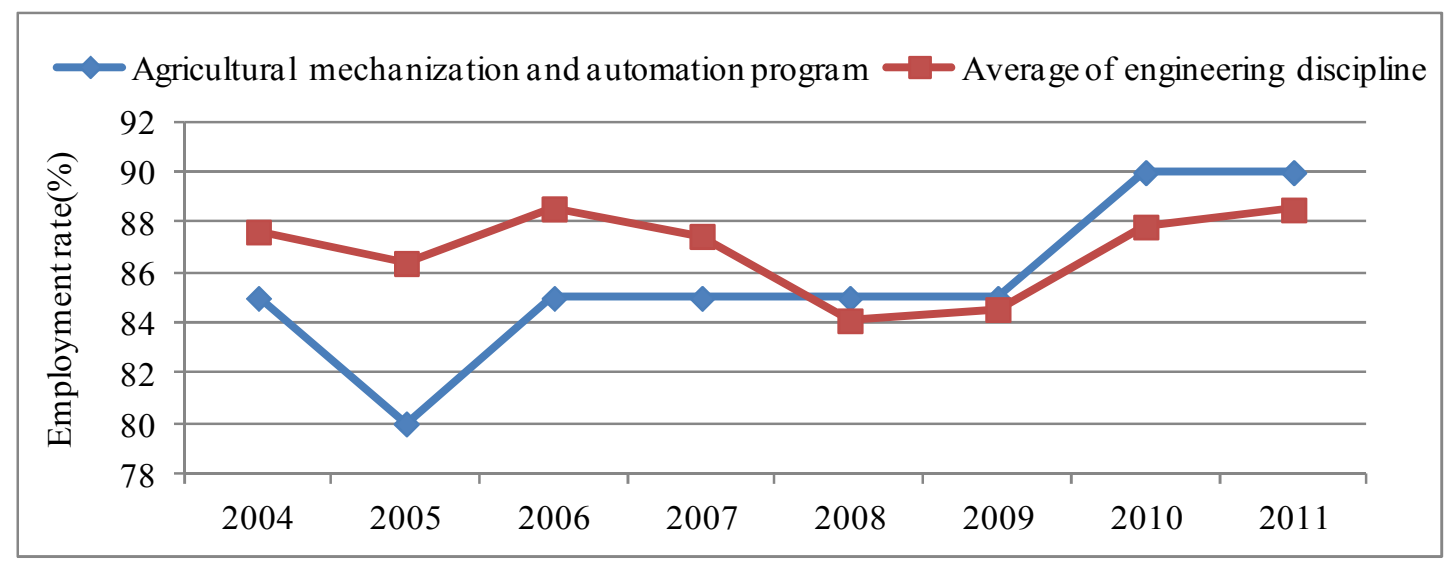

Fig. 3 Employment rate of agricultural mechanization and automation program in China

\section{Conclusions}

In this paper, we have presented a chronological evolution of AE education in China, the discipline has experienced three major stages:

The first talent training pattern represented a significant paradigm is derived from the liberal education in American. The curriculum of liberal education was designed to prepare students for the AE generalists by providing graduates with an invaluable set of employability skills, including the ability to critical thinking, communicate skills, and the capacity for lifelong learning.

The second talent training pattern named professional education represented another famous education paradigm is originated in USSR. Compared to the liberal education, the professional education provides the students with single knowledge structure and vocation ability, this type of education pattern can prepare graduates for a narrow field in study, and there is insufficient innovation in the workplace.

The third model is named inter-disciplinary talent cultivation model which is ongoing not only emphasis on the professional education, but also pay more attention to the importance of general education. Regardless of students' major, every college graduates should acquire broad knowledge in the liberal arts and sciences, as well as in-depth knowledge of the AE major field and complex problem-solving skills in real-workplace. The data of employment rate shows that the inter-disciplinary talent cultivation model provides graduates with good integrative skills and innovation spirit.

AE discipline is a key discipline that focuses of engineering skills and multidisciplinary approach to solving agricultural and environment problems, ensuring national food security. It will play a leading role in the development of China's modernized agriculture.

\section{References}

[1] L.U.Opara, J.S. Perret and D.B.Ampratwum, The evolution of agricultural engineering education and curriculum reform at Sultan Qaboos University, Int. J. Eng. Educ.6 (2006) 1139-1148. 
[2] Harvard Committee. General Education in a Free Society, Harvard University Press, Cambridge 1945.

[3] Information on http://lib.dr.iastate.edu/abe_eng_reports

[4] V.F. Zhilin and A.Ya. Savel'yev, The Former Soviet Union, In: N.P. Tarasova (Eds.), Quality of Human Resources : Education -Volume 2, Eolss Publishers Co. Ltd., Paris,2009, pp. 247

[5] K.M. Sufiana and X.Y. Wu, Chinese and Pakistani teachers' perspectives about quality oriented education of China, Global J. Hum. Soc. Sci. 8(2012) 37-47.

[6] The Boston Consulting Group and China Development Research Foundation, Developing mixed ownership structures and modern enterprise systems, The Boston Consulting Group ,2014.

[7] F. Cai, A. Park and Y.H. Zhao, The Chinese Labor Market in the Reform Era (2012), in: L. Brandt and T.G. Rawski (Eds.), China's Great Economic Transformation, Cambridge University Press, Cambridge (2008). 